\title{
ESTRUCTURAS MONOPOLISTICAS Y PUBLICIDAD: \\ EL SISTEMA DE DESINFORMACION FARMACEUTICA
}

Félix Lobo

«Del mismo modo que no tiene sentido deplorar las bajas de la guerra sin atacar su causa, la guerra, igualmente no tiene sentido tocar la alarma acerca de la publicidad y todo lo que la acompaña sin identificar claramente el "locus" del que emana la pestilencia: las empresas monopolísticas y oligopolísticas y las tácticas competitivas extrañas a los precios que les enfrentan y que constituyen un componente esencial de su "modus operandi"."

Paul A. Baran. (Del «Prefacio» a la Economia politica del crecimiento. Edición de Penguin, Harmondsworth, 1973, página 23.)

«Lo más seguro es que todo portavoz de la Industria te diga que sus más sobresalientes conquistas se han producido en el campo de la investigación. Pero aún es más probable que cualquier experto en marketing bien informado te diga que donde radican las verdaderas habilidades de la Industria Farmacéutica es en el área de la promoción de ventas.»

De la declaración de un testigo ante el Parlamento canadiense (citada por Henry B. Steele en la Investigación Nelson, parte 5, pág. 1917.) 
Casi todo el mundo sabe que los medicamentos son intensamente anunciados y que las empresas farmacéuticas gastan sumas enormes en publicidad. Pero aunque a muchos, principalmente médicos y farmacéuticos, su propia experiencia personal les sugiera visiones críticas del fenómeno, no suele tenerse una idea clara ni del sentido económico de este proceder ni de la magnitud de los costes sociales, en términos sanitarios, que origina. Aún está menos generalizada la noción de que la publicidad es un elemento esencial de la estructura monopolística del mercado farmacéutico y que, por consiguiente, tiende a sesgar de forma sistemática la información que transmite, creando un auténtico cuello de botella en un área básica de la asistencia sanitaria: la comunicación de los conocimientos farmacológios. El propósito al que pretende acercarse este artículo es triple'. Primero, resumir el sentido económico de la publicidad farmacéutica. Segundo, proporcionar evidencia acerca de su incapacidad, que creo demostrada «ad nauseam», para transmitir a los médicos información adecuada sobre los medicamentos que utilizan y, por tanto, para garantizar una asistencia sanitaria aceptable. Tercero, demostrar que la paradójica transmutación del sistema publicitario farmacéutico en un sistema de desinformación no resulta de la incapacidad aleatoria, o de la venalidad ocasional de tales o cuales compañías o ejecutivos de ventas, en estos o aquellos países, sino que es un humor necesariamente segregado por la estructura monopolística imperante en los mercados farmacéuticos capitalistas.

\section{SENTIDO ECONOMICO DE LA PUBLICIDAD FARMACEUTICA}

Las tres dimensiones fundamentales de la estructura económica de un mercado industrial son: el grado de homogeneidad o diferenciación de los productos; las barreras a la entrada de nuevas empresas competidoras potenciales, y el nivel de concentración económica alcanzado. Pues bien, lo característico de la publicidad farmacéutica es que afecta a dichas tres dimensiones a un tiempo y de forma interconexionada.

a) Los mercados de productos no homogéneos llevaron a E. H. Chamberlin y J. Robinson a lanzar a la palestra su polémico modelo de la competencia imperfecta o monopolística (2). El caso de los medicamentos confirma la regla general demostrada por Bain (3), pues la publicidad es el mecanismo básico de diferenciación:

«La Industria Farmacéutica no sólo ha tenido éxito al mantener entre muchos médicos y compradores la convicción de que los fárma-

' Sólo una investigación multidisciplinar puede alcanzar su consecución plena. Obsérvese, además, que este artículo se basa en un análisis económico-indur trial (1). Hasta cierto punto los materiales aquí aportados en función de los objetivos señalados en segundo y tercer lugar son subproductos ajenos a mi especialización. 
cos no son todos iguales, sino que incluso ha logrado persuadirles de que todos son diferentes, lo que, desde el punto de vista de las ventas, es un argumento mucho más efectivo... (Esto)... da al oferente una oportunidad única para marcar el precio sin tener que tomar en consideración ninguna restricción, como no sea lo que él cree que el mercado va a soportar. Por supuesto tendrá en cuenta... la presencia y éxito de productos comparables..., pero no, por definición, la de ningún producto exactamente igual, porque no hay ninguno» (4, testimonio de G. S. Squibb, ex vicepresidente de E. R. Squibb, el 14 de diciembre de 1967, parte 5, pág. 1580).

Una campaña iniciada en 1973 por Roche, empresa líder en muchos as. pectos, llegó a diferenciar tres marcas del mismo producto: dos de su exclusiva propiedad («Bactrim» y «Gantanol») y una tercera («Septra») de un licenciatario (Burroughs-Wellcome), aunque ello implicara manipular las indicaciones tẹrapéuticas (5, parte 3, pág. 1093).

b) La publicidad es una formidable barrera a la entrada en el mercado de nuevas empresas potencialmente competidoras de las ya existentes. Para lograr la perpetuación de las ventajas monopolísticas conseguidas con la diferenciación, las empresas establecidas, por medio de la publicidad, impiden el acceso al mercado de nuevos competidores atraídos por los beneficios extraordiarios. Primero, porque «los gastos de promoción de ventas tan extremadamente altos en que incurren las grandes empresas... elevan considerablemente los costes asociados con el lanzamiento de un nuevo producto» (6). Segundo, la publicidad farmacéutica utiliza métodos muy sofisticados. «Las empresas principales mantienen un amplio ejército de agentes de ventas que con sus bien establecidas relaciones con los médicos hacen muy difícil la entrada de nuevas compañías. Muchas empresas no americanas que hacen descubrimientos prefieren cederlos bajo licencia a empresas americanas antes que correr con el gasto de montar una red de ventas en los Estados Unidos» (7). Tercero, «la lealtad de marca obliga a suministrar más mensajes publicitarios por comprador potencial para inducirle a cambiar de marca, que en el caso de las compras repetidas... Así se crea una ventaja en costes... para los oferentes ya establecidos...» (8, pág. 425). Finalmente, el gasto publicitario supone «un empleo particularmente arriesgado de los fondos de la empresa, ya que no crea activos tangibles susceptibles de ser vendidos» (8, pág. 426).

c) En la publicidad existen economías de escala, nueva barrera alrededor del mercado farmacéutico, que coadyuva al incremento de los niveles de concentración. Pocas empresas pueden, así, llegar a dominar cada uno de los submercados especializados en que se divide y a los que aludo en (9). En los procesos productivos más característicos de la Industria Farmacéutica no existen economías de escala técnicas. Entonces «sería concebible que la Industria Farmacéutica... se aproximase a las condiciones de competencia pura» (10, 
página 135). En cambio existen «economías de escala derivadas de la efectividad creciente de los mensajes publicitarios por unidad de «output», así como del decrecimiento de los costes, según aumenta el número de mensajes publicitarios adquiridos (8, pág. 426). Ocurre así que «en la promoción de ventas... las grandes empresas gozan de una fuerte ventaja en lo que concierne a los costes... Las pequeñas empresas cada vez experimentan más dificultades para utilizar la publicidad más eficaz, a saber, los visitadores médicos, debido a sus altos costes... (y) se ven obligadas a consagrar a su publicidad un porcentaje de ventas más elevado que las grandes...» $(11$, páginas 63 y 64).

En resumen, la publicidad intensiva permite una acusada diferenciación de los medicamentos, que atribuye a los oferentes poderes monopolísticos generadores de beneficios extraordinarios. Estos perduran gracias a que los competidores potencialmente atraídos por ellos y que podrían disputárselos son disuadidos de entrar en el mercado por la cantidad y calidad de las actividades publicitarias. En el proceso, y debido, además, a la presencia de economías de escala publicitarias, las empresas pequeñas tienden a ser expulsadas, concentrándose cada vez más dichos beneficios y el mercado mismo en torno a las mayores.

\section{PUBLICIDAD Y NIVEL DE INFORMACION DE LOS MEDICOS}

El médico, como auténtico «agente de compras» del paciente, es quien decide casi todos los aspectos del consumo. Consiguientemente, «los médicos son el centro focal de las presiones publicitarias» (12, pág. 155). Pero la eficacia de éstas depende del nivel de información que aquéllos posean sobre los méritos relativos de los productos rivales. Su larga educación universitaria puede sugerir que la virtualidad de la publicidad para modificar sus pautas de comportamiento es pequeña. La propia Industria se ha descargado con este argumento de la acusación de incurrir en excesos publicitarios (13). Sin embargo, la situación real parece ser muy distinta. "Que los médicos tienen un conocimiento perfecto de los medicamentos es un estereotipo para consumo público promovido por las grandes empresas» (14, pág. 70).

En efecto, «la acusación de que facultades de medicina y asociaciones médicas... han dejado un vacío pronto ocupado por las campañas de publicidad de la Industria» (15, pág. 53) ha sido exhaustivamente documentada por las investigaciones del Senado norteamericano. «Desde segundo año, en que el doctor medio recibe el último curso organizado de Farmacología, la Industria Farmacéutica es... responsable en gran medida de la educación sobre medicamentos» (4, Testimonio del doctor Holloman, parte 1, pág. 32). A los propios consumidores-pacientes les «parece como si los médicos hubieran sido forzados a abdicar de su responsabilidad profesional a la hora de determinar 
la terapia medicamentosa... en favor de la Industria Farmacéutica» (4, Tes. timonio del doctor Haddard, parte 1, pág. 50). También por el doctor Burack (16, pág. 3) y, muy especialmente, por un grupo de estudio «ad hoc» del Departamento de Sanidad:

"En la mayor parte de las facultades de medicina americanas el curso principal de Farmacología se imparte durante el segundo año. En general éste es el único contacto formal de los estudiantes con el tema. Después... la mayor parte no reciben enseñanza formal sobre los aspectos prácticos de esta ciencia - Farmacología Clínica-, sino que se les deja que adquieran la experiencia práctica que sean capaces de absorber de una diversidad de cursos en los distintos cuerpos de la medicina clínica. La crítica más seria que quizás puede hacerse de este aprendizaje informal es que no proporciona al futuro médico las actitudes científicas y críticas que son esenciales de cara al empleo de los fármacos y para evaluar la publicidad. Llegamos a la conclusión de que la capacidad del médico individual para adoptar decisiones equilibradas bajo condiciones bastante confusas es en la actualidad objeto de serias preocupaciones entre médicos, científicos y profesores eminentes» $(17$, página 22).

El problema no es sólo americano. La enseñanza de la medicina suele considerarse ejemplar en Inglaterra, pero el mismo presidente de la «Medicines Commission», Sir Ronald Bodleley-Scott, afirmó que «los doctores de mi generación, particularmente los de medicina general..., no tienen ni idea de cómo usar, digamos, el 90 por 100 de los fármacos modernos... En la facul. tad nunca les enseñaron nada de Farmacología Clínica o Terapéutica AplicaJa» (18). Con toda generalidad y con toda su autoridad, la Organización Mundial de la Salud (OMS) ha dicho:

«En los últimos años se ha llegado al convencimiento de que las enseñanzas de Farmacología fundamental dispensadas en las escuelas de medicina no bastan para dar a los médicos los conocimientos científicos y la actitud crítica indispensable para el uso acertado de los medicamentos modernos... La enseñanza se aleja cada vez más de los fundamentos científicos de la Farmacología... El problema es que los especialistas en Farmacología Clínica escasean mucho...» (19).

La cuestión, no obstante, no radica sólo en una manifiesta insuficiencia de los métodos educativos. Está claro que la estructura monopolística del mercado fomenta sustancialmente la confusión de los médicos con la proliferación de productos y denominaciones, creando un círculo vicioso difícil de romper. Resulta así que, alcanzado un nivel determinado, la diferenciación 
del producto por sí sola genera una diferenciación aún mayor. Más que de "vacío educativo" se debería de hablar de un hoyo, como el de San Agustín, imposible de llenar y fácil de esgrimir, como hacen Cooper (20, pág. 207) y la misma OCDE (11, pág. 86), para «justificar» la «necesidad» de la publicidad.

Algunos estudios han tratado de determinar cuantitativamente la importancia relativa de las fuentes de información utilizadas por los médicos en el ejercicio de su profesión. En (4, parte 3, págs. 874 y ss.) y (14, pág. 70) se citan trabajos ya antiguos. El doctor Simmons, director del "Bureau of Drugs» de la «Food and Drug Administration», ha resumido así los más recientes:

«Tres estudios en los que se preguntó a los médicos por su fuente primaria de información apuntaron al visitador médico de un 31 a un 52 por 100 de las veces; a las revistas médicas, de un 9 a un 25 por 100 , y a la publicidad por correo, de un 16 a un 22 por 100 . Si un cuarto de las noticias extraídas de revistas fueran anuncios incluidos en ellas, parece que entre la mitad y tres cuartos de las veces la información inicial sobre nuevos productos procedería de la publicidad de las compañías farmacéuticas, cuyo interés radica en que el médico los utilice. Una encuesta realizada por Coleman y asociados reveló que el 21 por 100 de los médicos recetaron en base a la publicidad directa de una compañía farmacéutica, y otro 21 por 100 por lo que leyeron en una revista publicada por ella. Ferber y Wales descubrieron que por lo menos el 39 por 100 (de los médicos) fueron inducidos a usar el nuevo medicamento por la publicidad del vendedor, mientras que en el estudio de Gaffin la cifra correspondiente llegó al 67 por 100. Cuando éste preguntó a los médicos por las fuentes más importantes para familiarizarse con las nuevas medicinas, el 68 por 100 especificó al visitador médico; el 32, los anuncios de las revistas; el 25, los anuncios por correo, y el 22, las muestras... En una encuesta más reciente el 62 por 100 de los médicos citó entre las tres primeras fuentes de información preferidas las de la Industria Farmacéutica, y sólo un 35 por 100 se refirió a las revistas médicas, las reuniones o las conversaciones con sus colegas. De las dos encuestas parece deducirse que los médicos consideran que la publicidad de la compañía vendedora es dos veces más importante que la información que les llega de sus compañeros de profesión» (21).

El mercado farmacéutico no es, pues, distinto en el aspecto aquí tratado de los demás, a pesar de las peculiares características culturales que confluyen en los médicos. Estos «generalmente responden a la publicidad del mismo modo que lo hacen otros consumidores, por mucho que la idea les es- 
candalice» (22). Queda así espacio abierto en la realidad para el despliegue de preocupantes contradicciones. El doctor Dale Console, director médico de la gran empresa farmacéutica Squibb hasta que "llegué a un punto en el que no podía soportame a mí mismo» y dimitió, se ha preguntado:

«¿Cómo puede competir la educación auténtica con las distorsiones cuidadosamente diseñadas que llegan a casa..., con los envíos postales semanales, las visitas regulares del representante, los anuncios a doble página y los que aparecen seis veces en la misma revista? Todo ello sin mencionar el estímulo adicional del guateque gratis y el equipo de golf con tres pelotas en las que se han grabado los nombres del médico y de la compañía en colores chocantes. La publicidad farmacéutica induce a los médicos a creer que hay vías facilonas de practicar la medicina» (5, parte 1, pág. 143).

Pero nadie mejor que un empresario para explicitar la contradicción básica:

«Los anuncios de las empresas farmacéuticas, como los de otros productos, tienden a insistir en lo bueno y a subestimar lo malo. Después de todo si estamos en el negocio es para vender y sacar un beneficio. No quiero decir que vayamos a tratar de vender productos que puedan ser peligrosos, malos o... lo que sea. Pero no puedes poner todo lo malo en los grandes titulares» (23).

\section{EL MERCADO FARMACEUTICO COMO MERCADO PUBLICITARIO REDUCIDO}

La intensidad con que la propaganda afecta a la estructura del mercado se ve muy reforzada por el hecho de que la soberanía del consumidor reside en el médico, pues el abanico de métodos publicitarios que ello abre ante los departamentos de promoción de ventas tiene una amplitud impensable en stros mercados. Dado que el número de médicos, por comparación a la población total, siempre es reducido, resulta que, a efectos publicitarios, el mercado farmacéutico es un mercado muy reducido también y muy concentrado, en el que a esfuerzos propagandísticos iguales a los realizados en otros mercados corresponden efectos incomparablemente superiores. «Se trata de un mercado relativamente pequeño y bien definido que puede ser intensamente saturado» (10, pág. 149). El ejemplo de los Estados Unidos es aleccionador:

«La Industria Farmacéutica gastó en 1971 más de mil millones de dólares en publicidad... Además, el número de personas sobre las que deben influr los fabricantes es relativamente pequeño... La adquisición 
de medicamentos con receta por parte de más de doscientos millones de personas puede ser controlada por la propaganda dirigidos a sólo doscientos mil médicos. Esto quiere decir que lo gastado anualmente en persuadir a cada médico para que recete llega a los cinco mil dólares» (5, Declaración del senador G. Nelson, parte 1, pág. 139).

La concentración de la propaganda no sólo obliga al médico a soportar una presión publicitaria inusitada, sino que, además, hace posible el empleo de técnicas que por su coste están proscritas en otros mercados: el contacto personal, mediante vendedores, con todos y cada uno de los médicos. No creo que se pueda encontrar otro mercado de productos de consumo en el que sea factible promocionar ventas utilizando como medio básico el contacto personal con todos los consumidores.

\section{VOLUMEN MONETARIO Y FISICO DE LA PROMOCION DE VENTAS}

El volumen de la publicidad farmacéutica «hace ya tiempo que ha alcanzado proporciones asombrosas» (17, pág. 31). Tener idea de su magnitud resulta útil por lo menos por tres razones: 1) El gasto monetario es, obviamente, la primera anotación entre los costes sociales originados. Scherer, que ha estimado el gasto publicitario americano en un 2 por 100 del Producto Nacional Bruto, considera que «una porción de tales recursos constituye un derroche patente» y que «los esfuerzos de promoción de los fabricantes farmacéuticos representan un ejemplo destacado» de tal derroche (24). 2) Si el volumen publicitario es muy alto puede transformar cualitativamente los efectos de la diferenciación del producto y elevarla a un plano nuevo. 3) Si los gastos de publicidad interponen una barrera de entrada a la industria, la altura que ésta alcance vendrá determinada por la magnitud de aquéllos.

La información cuantitativa sobre promoción de ventas no resulta fácil de obtener. Es un importante secreto comercial y también, frente a la opinión pública - Cooper (20) pretende que «la Industria Farmacéutica está lejos de ser el primer sector en cuanto a gastos publicitarios» (pág. 214). Pero, según la tabla de la página siguiente, «Household Medicines and Toiletries» ocuparían el primer lugar de la lista, y «Medicamentos con Receta», el cuarto-. Cuando hay pocas estadísticas es difícil, además, que las existentes estén convenientemente normalizadas ${ }^{2}$.

La evidencia a pesar de todo disponible puede resumirse en seis puntos:

1. Las empresas farmacéuticas gastan en publicidad, como media, por lo menos, un 20 por 100 de sus ventas. Recuérdese al respecto que «hay

2 De definir las remuneraciones de los visitadores como gastos de publicidad a sumergirlas entre los de personal puede mediar un abismo. 
evidencia suficiente en la literatura de "marketing" acerca del amplio uso de la fijación "a ojo" de un porcentaje fijo sobre ventas como presupuesto de publicidad» (26). Se trata del segundo coste en importancia - tras los gastos de fabricación, incluyendo el producto en sí- y a veces incluso del primero (11, págs. 66 y 67; 12, pág. 157; 25, pág. 108).

2) El gasto publicitario absoluto alcanza una cifra importantísima. Para 1970 Sanjaya Lall lo estimó, sólo en los países desarrollados, en unos $3.000 \mathrm{mi}$ llones de dólares (27).

3. Las empresas pequeñas se ven forzadas a dedicar más recursos en términos relativos a publicidad que las grandes. Datos proporcionados por Cooper (20, pág. 40) y la Comisión de Monopolios Británica (28, pág. 40) indican que aquéllas pueden gastar hasta el 30 o el 40 por 100 de sus ventas, mientras que éstas no necesitan pasar del 10 por 100 . Está claro, pues, que «las tácticas de marketing originan economías de escala que no existen al fabricar medicamentos» (29).

4. En la Industria Farmacéutica los gastos de publicidad son entre dos y cuatro veces superiores a los de investigación y desarrollo.

5. Los gastos de publicidad farmacéutica son un múltiplo de los presupuestos de educación superior médica. Ya el Informe Kefauver destacó que en 1958 en Estados Unidos los primeros ascendieron a unos 750 millones de dólares y los segundos a sólo 200 (12, pág. 157). Más recientemente $y$ en el mismo país se ha recordado que la publicidad farmacéutica «excede con mucho en términos de coste los presupuestos combinados de administración y educación de todas las facultades de medicina juntas» (16, pág. 7).

6. De todas las industrias de bienes de consumo, la farmacéutica es una de las que más gastan en publicidad. Comanor y Wilson con datos antiguos (años 1954-1957), pero fiables, homogéneos y amplios (8) muestran que de 41 industrias, 25 gastan menos del 3 por 100 de sus ventas; ocho entre 3 y 6 por 100 y sólo media docena tienen ratios que superan el 6 por 100. La Farmacéutica con un 10 ocupa el segundo lugar de la lista (detrás de Perfumes, con un 15) ${ }^{3}$. Wilder (26) informa de que en 1967 es la que tiene gastos absolutos más elevados $(73+$ millones de dólares $)$; en porcentaje sobre ventas sus gastos son terceros, tras Cosméticos y Jabones y Detergentes. En 1948 sus ventas eran el 2,3 por 100 del total del grupo de 27 industrias de consumo consideradas y su presupuesto de publicidad el 4,5 por 100 . En 1967 estas cifras pasaban a ser el 11,8 y el 16,8 por 100 , respectivamente ${ }^{\star}$. Buenas ex-

Este porcentaje del 10 por 100 está por debajo y en conflicto con otros aquí recogidos. Las razones estadísticas que justifican esta discrepancia están perfectamente aclaradas en (4, parte 5 , pág. 2046). Ocurre que los datos del Internal Revenue Service utilizados infravaloran los gastos de publicidad y sobrevaloran los de ventas, pero eran los únicos homogéneos utilizables en un cross-section amplio.

A estos datos se aplican también las salvedades de la nota anterior. 
presiones todas ellas del «boom» de ventas de los años cincuenta y sesenta y del papel jugado por la publicidad.

Altos gastos se materializan en elevados volúmenes físicos de material publicitario. Literalmente abrumados, muchos médicos se han preocupado de medirlos, contarlos o pesarlos. En (4, parte 1, pág. 326) se revela que un médico, en un mes, recibió 48 muestras procedentes de 44 compañías, con un peso superior a los dos kilos; 125 anuncios por correo, que pesaron más de cinco kilos, y 41 periódicos y revistas, enviados por 18 compañías, con un peso total de 8 kilos.

Un interesante «caso práctico» de las actividades publicitarias de las compañías farmacéuticas lo proporciona la filial inglesa de Hoffman-La Roche, Roche Products (28, págs. 16, 22, 25 y 39). En 1970 empleaba 66 visitadores que realizaron 58.500 visitas. Envió 258 textos publicitarios por correo a 51.707 destinos (médicos, farmacéuticos, hospitales...) y 25 revistas inglesas le incluyeron anuncios equivalentes a 500 páginas enteras. E] cuadro 1 , usando sus propios datos, proporciona la distribución de sus gastos en publicidad, inferiores a la media inglesa que (con las reservas expuestas sobre la significación de estas mediciones) se acercaba en 1965 al 15 por 100 de las ventas, según el Informe Sainsbury (25).

\section{CUADRO 1}

Distribución de los gastos de publicidad de Rocbe Products en Inglaterra (miles de libras)

\begin{tabular}{|c|c|c|c|}
\hline & 1966 & 1968 & 1970 \\
\hline $\begin{array}{l}\text { Revistas y publicidad por correo } \\
\text { Equipo de campo (visitadores): }\end{array}$ & 337 & 403 & 650 \\
\hline Salarios, gastos y administración $\ldots \ldots \ldots \ldots \ldots$ & 246 & 343 & 485 \\
\hline Muestras y material de promoción $\ldots \ldots \ldots \ldots$ & 68 & 89 & 177 \\
\hline 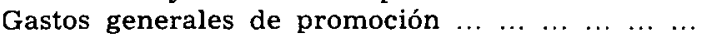 & 53 & 94 & 183 \\
\hline TOTAL $\ldots \ldots \ldots$ & 704 & 929 & 1.495 \\
\hline $\begin{array}{llllllll}\text { Porcentaje sobre ventas } & \ldots & \ldots & \ldots & \ldots & \ldots & \ldots\end{array}$ & 10,7 & 9,5 & 11,2 \\
\hline
\end{tabular}

Fuente: (28, pág. 40).

Finalmente, conviene apuntar que el volumen de la publicidad farmacéutica convierte a la Industria Farmacéutica en uno de los mejores mercados del propio sector publicitario. Se trata de una conexión que por la magnitud de los intereses en juego no puede ser olvidada.

\section{METODOS PUBLICITARIOS}

La presión publicitaria farmacéutica no sólo es grande sino también diversificada ${ }^{5}$. El instrumento publicitario típico de este mercado es el visi-

s Un excelente ejemplo de una campaña completa de promoción farmacéutica puede leerse en (22). 
tador médico. El Informe Kefauver (12, págs. 157 y ss.), el Informe Sainsbury (25, pág. 64), Eurofinance (30) y casi todos los estudios han confirmado que «origina la mayor parte de los gastos totales de promoción de ventas probablemente en todos los países» (11, pág. 84), y es la fuente de información sobre nuevos productos más importante (21). Hay que tener en cuenta que «la influencia personal... parece más persuasiva, en general, que cualquiera de los medios de comunicación de masas» y que «como mejor se catequiza es con el uso combinado de varios medios masivos unidos al contacto personal directo» (31). Pero hay métodos alternativos o complementarios, cuya eficacia se despliega a niveles diversos. Algunos son, además, sutiles. No tratan de incidir exclusivamente sobre el colectivo de los médicos, ni siquiera sobre el de los pacientes en cuanto tales, sino sobre la sociedad globalmente considerada. Se trata de propiciar el consumo de fármacos como componente «normal» de la vida moderna y de defender la «imagen» de la industria. Si ampliamos la noción de promoción de ventas, quizá los instrumentos publicitarios más poderosos sean precisamente los que indirectamente actúan sobre la sociedad en general como publicidad encubierta.

\section{a) Catálogos-diccionarios}

La frecuencia con que son consultados por los médicos y el hecho de que generalmente se desconozca que su contenido es publicidad pagada me animan a tratar de ellos en primer lugar.

«Senador Nelson: ¿Hay alguna fuente a la que el médico pueda recurrir... cuando quiera recetar el mejor fármaco, al precio más económico para su paciente, que relacione... el nombre genérico y todas las marcas con las que se comercializa, y los precios, y los efectos secundarios... y que le dé información sobre sus equivalentes terapéuticos?»

«Doctor Holloman: No conozco ningún libro tan completo como el que usted describe» $(4$, parte 1 , pág. 33$)$.

La pregunta del senador Nelson era totalmente pertinente. Los mercados con gran variedad de productos se hacen transparentes con catálogosdiccionarios periódicamente actualizados, en los que figuran nombres, precios y características más relevantes de las mercancías. El farmacéutico no es una excepción. En todos los países existe un catálogo de medicamentos a disposición de los médicos. La peculiaridad estriba en que su información no suele ser completa y, sobre todo, no suele ser independiente. En los Estados Unidos en $197+$ la "Food and Drug Administration "comprobó que el 97 por 100 de los médicos emplean el Pbysicians Desk Reference (PDR), una media de 7,5 veces a la semana como fuente de información (32). 
«Su contenido es publicidad, aunque muchos médicos y más pacientes no sean conscientes de ello. La publicidad se paga en el PDR a razón de 115 dólares por columna y pulgada» (4, Declaración del Dr. Burack, parte 1, pág. 320).

De este libro, que se distribuye gratuitamente a los 200.000 médicos americanos y también a farmacias y hospitales a un precio nominal, y cuya empresa editora es Medical Economics Inc, hasta 1967 se podía afirmar que «las compañías compran el espacio del PDR y publican lo que quieren publicar... Como el PDR es un catálogo publicitario, es incompleto y sólo menciona de forma prominente unos pocos nombres genéricos...» (16, página 18). «La mayor parte de los médicos no son conscientes de esto... involuntariamente son influidos en su ejercicio por intereses comerciales extraprofesionales» (16, pág. 20). Desde 1967 la autoridad sanitaria americana vela por que la información del PDR sea completa y fiable. Pero hay as pectos referidos a calidad técnica y sobre todo a la transparencia del mercado que siguen sin ser resueltos: ni los nombres genéricos ni los precios aparecen de forma relevante.

En Francia (33), Alemania (34), Italia (35), Inglaterra (36), España (37, $38,39)$, y otros países existen catálogos parecidos, aunque menos controlados. El francés de 1973 dice que «la tirada... realizada con el concurso de los laboratorios nos permitirá servir a título gratuito... a más de 48.000 médicos». Su lista de denominaciones comunes sólo incluye unas 1.100 especialidades equivalentes, pero el cuerpo del diccionario recoge más de 6.000 marcas.

\section{b) Los visitadores médicos}

En este mercado el agente de promoción de ventas o representante comercial es conocido, por obra del sistema publicitario, siempre atento a la persuasión lingǘstica, con la expresión "visitador médico»". Se trata obviamente de un eufemismo. Oculta el contenido comercial de la función desempeñada; destaca su pura apariencia material (hacer visitas); y con el calificativo «médico» no se sabe si hace referencia a la categoría profesional de quien es visitado o al halo cientifista con el que se pretende rodear al visitante. Dos son sus características básicas: Primero, es el método publicitario más eficaz y en él vuelcan las compañías sus esfuerzos. Segundo, la comunicación médico-visitador es estrictamente personal, casi íntima, y por ende inasequible a todo control.

* El término está copiado del francés. En inglés se usan las expresiones detailman" (USA) y "representative" (Inglaterra), mucho más realistas y menos pedantes. 
«... Los visitadores... (son)... el mecanismo de comunicación (publicitario) más poderoso, y la industria (en Estados Unidos) les dedica por lo menos 700 millones de dólares (siete décimas partes de los gastos totales de publicidad). Mientras que la «Food and Drug Administration» puede inspeccionar la publicidad impresa, es físicamente imposible controlar lo que los miles de visitadores cuentan a los médicos» (5, Declaración del senador G. Nelson, parte 1, pág. 141).

La figura del visitador, tan conocida por los médicos, es bien descrita en los textos que siguen:

«Examinemos al típico visitador. Casi siempre se trata de un caballero agraciado y bien vestido; generalmente su nivel educativo es alto y se halla en posesión de un título medio. Con bastante frecuencia ha seguido algún curso de iniciación sanitaria; en algunos casos es un licenciado en farmacia y no es raro que haya pasado algún tiempo en la facultad de medicina. Así pues nos encontramos con un hombre que posee algunos conocimientos científicos y que puede hablar con el médico más o menos en sus propios términos. Hace la parodia de ser un educador o, al menos, su empresa insiste en su papel de educador médico» (4, Declaración del Dr. Small, parte 1, pág. 353).

«¿Quién es el visitador? Un representante de medicamentos no es un vendedor ordinario. Es verdad que a veces gana sus comisiones en función de sus ventas, como pasa con otros vendedores; pero ahí termina el paralelismo, porque aquél no sólo está encargado de vender su producto sino también de "no venderlo"... Para persuadir al médico a que use sus fármacos inevitablemente debe discutir, además de sus méritos, sus desventajas. El Representante Ubicuo es el título de mi artículo... Es ubicuo en el verdadero sentido del término. Para las profesiones médicas y sanitarias es omnipresente. Se le puede encontrar en la consulta del médico, en la farmacia, en los pasillos de los hospitales hablando con internos, residentes y personal ayudante. Está en el despacho de la enfermera y a la puerta de las unidades coronarias $y$ de vigilancia intensiva... En las facultades de medicina y odontología, en las escuelas de enfermeras, en los congresos médicos, seminarios y exposiciones; incluso en la cafetería del hospital tomando algo con un médico, un farmacéutico, un gerente o un miembro del comité de selección de medicinas» (5, Declaración del ex visitador del Merck, Co., B. Wasserman el día 8 de marzo de 1974, parte 3, pág. 723).

Sólo el reducido tamaño del mercado publicitario farmacéutico permite el empleo de un método tan caro y tan efectivo como el del contacto personal. En 1959 el Comité Kefauver estimó el coste de cada visita en unos 
9 ó 10 dólares, que, multiplicados por los 150.000 médicos americanos daban lugar a un gasto total de 1,5 millones de dólares por visita. El gasto por visitador y año se estimó por aquel entonces en unos 15.000 dólares en la empresa Merck, 14.000 en Upjohn, 16.000 en Lederle, 20.000 en S.K.F., 12.000 en Ciba, la mitad aproximadamente en concepto de salario y la otra mitad como dietas y gastos varios (12, pág. 159). Diez años después la OCDE hablaba de un coste por visita en el mismo país de unos 20 dólares (11, pág. 84). Las numerosas plantillas de visitadores de las empresas, de las que no parecen existir informaciones precisas aparte de las consignadas en el cuadro 2, explican finalmente por qué los visitadores son el gasto publicitario «estrella»y, en buena medida, la magnitud de los propios gastos de publicidad.

\section{CUADRO 2}

USA 1958. Número de visitadores. Compañias seleccionadas

\begin{tabular}{|c|c|c|c|}
\hline & Visitadores & $\begin{array}{c}\text { Personal } \\
\text { total }\end{array}$ & $\%$ \\
\hline \multicolumn{4}{|l|}{$\begin{array}{lllllllllllllll}\text { Upjohn } & \ldots & \ldots & \ldots & \ldots & \ldots & \ldots & \ldots & \ldots & \ldots & \ldots & \ldots & \ldots & \ldots & \ldots\end{array}$} \\
\hline 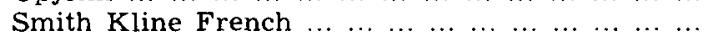 & 1.030 & 5.700 & 18 \\
\hline 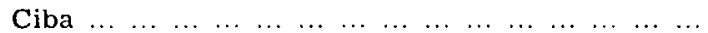 & 400 & 3.000 & 13 \\
\hline $\begin{array}{llllllllllllll}\text { Parke Davis } & \ldots & \ldots & \ldots & \ldots & \ldots & \ldots & \ldots & \ldots & \ldots & \ldots & \ldots & \ldots & \ldots\end{array}$ & 300 & 1.500 & 20 \\
\hline & 1.540 & 10.980 & 14 \\
\hline
\end{tabular}

Fuente: (5, pág. 158).

El problema, además, parece que no es sólo de altos costes sino de una productividad muy baja. Según una encuesta encargada por el Comité Sainsbury sólo uno de cada ocho médicos consideraba a los visitadores como la mejor fuente de conocimiento, y menos de la mitad se mostraban decididos a emplear un fármaco con los solos datos proporcionados por el visitador.

«Si esto es así es que la publicidad como fuente de información es una forma de proporcionarla muy derrochadora. Aún es más dudoso decidir si la nación como ente distinto de las empresas, está obteniendo justa contrapartida por los siete millones de libras gastados en visitadores en $1965 \ldots$. Parece que un cuarto de las visitas se frustran y no llegan a tomar contacto con los médicos... Una porción sustancial (de éstos) dijeron que si no recibieran a ningún visitador no perderían una fuente de información importante. Más de la mitad declararon que durante el año último toparon en ocasiones con visitadores que no tenían conocimientos suficientes para decirles todo lo que querían saber. Está claro que las empresas (farmacéuticas) compran el tiempo de 
los médicos a un coste extraordinariamente alto» (25, págs. 69,70 y 71).

Que los visitadores constituyan la primera rúbrica publicitaria se explica también por la característica «libertad» en que tiene lugar la transmisión de la información. El Informe Kefauver ya afirmaba que «el problema específico que presentan los visitadores es la dificultad si no imposibilidad de controlar la exactitud de la información que transmiten a los médicos... las oportunidades para transmitir información desorientadora son en verdad muy reales» (12, págs. 181 y 192). En el mismo sentido se expresaba el Informe Sainsbury al destacar «... la tendencia a supervalorar los méritos de un producto y a ocultar sus efectos secundarios. Como cuando un visitador está con el médico no hay testigos, es muy difícil obtener evidencia sobre estas cuestiones» (25, pág. 68). Las investigaciones del Senado americano y las facultades de que goza constitucionalmente para recabar información han permitido documentar el carácter no científico, meramente publicitario $\mathrm{y}$, a veces, desorientador, inmoral y atentatorio contra la salud pública de la información que transmiten los visitadores a los médicos. $\mathrm{Y}$ todo ello no como desviación esporádica lógica en vendedores que quieren maximizar sus comisiones sino como estrategia de ventas formalmente adoptada por todas las empresas, incluso las más conocidas. En el anexo recojo, como botones de muestra, detalles de campañas propagandísticas de Parke Davis (contrarrestando la información sobre los graves efectos secundarios del Cloranfenicol/Cloromicetín, antibiótico de uso generalizado); Sandoz (instrucciones para minimizar teatralmente las contraindicaciones del tranquilizante Mellaril), y de Searle (cómo corromper a médicos y enfermeras).

Las empresas han querido reconducir el problema al cómodo terreno de la formación de los visitadores. Promesas, planes y declaraciones acerca de su mejora son continuos. Un análisis prospectivo ha "predicho» que «la política publicitaria de las compañías habrá de adaptarse a las "nuevas" condiciones: incremento de médicos en hospitales o consultas en grupo; intensificación de la educación para posgraduados; restricciones gubernamentales a un aumento excesivo de los gastos. Las empresas habrán de emplear visitadores más cualificados...» (40). En algunos países incluso funcionan escuelas y se exigen exámenes. Pero Cooper ha dicho que el «número de visitadores graduados o semigraduados universitarios desciende, porque a las empresas no les gustan. Prefieren instruir a los vendedores según su estilo propio. Aún más, las personas con educación cualificada no están tan dominadas en sus perspectivas por lo comercial y tienden a dispersarse hacia productos distintos del que han de vender o a discutir con el médico de igual a igual» (20, pág. 220). 


\section{c) Revistas médico-científicas}

Las revistas científicas constituyen un medio decisivo de transmisión de los conocimientos, avances e investigaciones médicas. En cuanto posibles portadores de publicidad, Silverman y Lee las clasifican en tres grupos (15, pág. 68): 1) Revistas de pago muy especializadas, de poca tirada, que no llevan publicidad o sólo unos anuncios bien separados del texto ${ }^{7}$. 2) Revistas gratuitas publicadas por asociaciones de médicos, de gran tirada y, en general, una reputación científica merecida, pero que incluyen gran cantidad de anuncios ${ }^{8}$. 3) Revistas propiedad de compañías privadas, gratuitas, de altas tiradas, abrumadora proporción de anuncios y con un contenido muchas veces en absoluto científico ${ }^{9}$. En el grupo segundo el mensaje publicitario se asocia al prestigio científico de la publicación; en el tercero, al brillante contenido en imágenes e incluso en textos literarios.

El volumen y el impacto de la publicidad inserta en todas estas revistas no pueden ser menospreciados. En los Estados Unidos «en 1970, de las cinco revistas profesionales con mayor volumen de publicidad pagada, cuatro eran médicas» (15, pág. 56), y en Inglaterra, «en una de las revistas importantes que examinamos, los anuncios de medicinas ocupaban casi el 60 por 100 del espacio publicitario. En otra, casi el 40 por 100 del espacio se dedicaba a anuncios. Todos los editores a quienes consultamos insistieron en el importante papel que juegan los anuncios de medicinas en la financiación de sus revistas" (25, pág. 64$)$.

La dependencia financiera hace dudar de la independencia editorial. Especialmente en las revistas con aureola científica la sumisión a los intereses comerciales puede tener consecuencias funestas. Por eso, incluso el famoso estudio del Ministerio de Sanidad americano se mostró sensible a esta cuestión (17, pág. 10). Lamentablemente, ciertas pruebas demuestran el éxito del asalto a la independencia editorial. En primer lugar, es preciso mencionar una incongruencia nada rara:

«En una revista (médica) apareció un artículo que señalaba los serios defectos y peligros de un medicamento. Esa misma revista lo había estado anunciando y siguió haciéndolo durante tres meses...» (4, Declaración del Dr. Cherkasky, parte 2, pág. 683).

En segundo término parece que hay connivencias triangulares entre industria, redactor del artículo y editor:

$?$ Entre ellas hay que incluir dos anglosajonas muy importantes dedicadas a la evaluación independiente de medicamentos, The Medical Letter, en USA, y The Prescriber's Journal. en Gran Bretaña (esta última con apoyo estatal).

${ }^{8}$ Como botones de muestra hay que mencionar el Journal of the American Medical Assocation y el New England Journal of Medicine, en los Estados Unidos, y el British Medical Journal y Lancet, en Gran Bretaña.

Entre las americanas destaca Medical Economics. 
«Un número sustancial de los así llamados artículos científicos... se escribe tras las puertas de las empresas farmacéuticas interesadas. Frecuentemente el médico firmante sólo hace las observaciones empíricas; sus datos, muchas veces incompletos y acríticos, se someten a un médico escritor empleado por la empresa. Este prepara el artículo y lo devuelve al firmante, quien hace el "esfuerzo" de enviarlo para su publicación... frecuentemente a una de las revistas que esperan publicidad de la empresa y que rara vez se niega a imprimirlo. No importa mucho de qué revista se trate; lo que primariamente preocupa es que el artículo se publique, sea donde sea, para poder hacer separatas... En una ocasión me asignaron la tarea de escribir uno acerca de una formulación nueva de un antibiótico de amplio espectro. Me dijeron que ya había sido aceptado para su publicación y antes de que lo hubiera terminado ya habían encargado 100.000 copias. El artículo, por supuesto, se publicó en el momento previsto que, por casualidad, coincidió con la puesta en venta del producto» (12, Declaración del Dr. Weinstein, ex empleado de Pfizer, pág. 182).

Burack recoge una carta-tipo confeccionada por Richardson-Merell y dirigida a Medical World News en la que el médico firmante-testaferro muestra su "desacuerdo" con un artículo que exponía la toxicidad de uno de sus productos (MER-29). La carta apareció efectivamente en la revista el 15 de julio de 1960 . El documento vio la luz en una reclamación judicial por lesiones debidas a la toxicidad de la droga (16, págs. 81 y ss.).

También en Inglaterra se han denunciado situaciones similares:

«Algunas revistas de gran reputación como el British Medical Journal han publicado artículos escritos por asesores que trabajan a plena dedicación en empresas farmacéuticas. Muchos autores considerados independientes en realidad se han vendido a la Industria y han aceptado realizar investigaciones con el único propósito de conseguir recompensas de algún tipo, desde un viaje al extranjero hasta un instrumento, unas comidas, una serie de artículos publicados o, simplemente, dinero» (41).

Por último Silverman y Lee han suministrado datos suficientes para pensar que la revista científico-médica más leída del mundo, el Journal of the American Medical Association (JAMA), se ha visto influida en su línea editorial por los intereses de la Industria (15, págs. 70 y ss.). Difícilmente puede tal cosa resultar extraña cuando la Investigación Kennedy desveló que los 34 millones de dólares de presupuesto de la «American Medical Association 
en 1973 se allegaron del siguiente modo (5, parte 4, pág. 1340); véase también 15 , pág. 68):

Además de interrumpir en 1955 sus análisis de calidad de las medicinas y de control de la publicidad, frente al problema de los nombres genéricos JAMA cambió su línea editorial, constituyéndose en uno de sus principales enemigos. Otro tanto ocurrió con su actitud frente a las asociaciones medicamentosas.

\section{d) Otra publicidad escrita}

En casi todos los países los médicos reciben por correo abrumadoras cantidades de anuncios de medicamentos en forma de folletos, tarjetones, desplegables, etc. Las opiniones sobre su volumen excesivo e ínfima calidad son unánimes. En la Investigación Kefauver y sobre la base de su propia experiencia, un médico estimó que si Correos hubiese de entregar en una sola ciudad la diaria carga de circulares y muestras farmacéuticas enviadas a los médicos americanos, necesitaría dos vagones de ferrocarril, 110 camiones grandes y 800 carteros. Después harían falta 25 camiones de basura para acarrearlos al vertedero y quemarlos en una pira cuya llama se vería a 50 millas de distancia (12, pág. 160). En Inglaterra «cada médico de cabecera recibe una media diaria de siete piezas publicitarias por correo» (25, pág. 64). El «Royal College of General Practitioners» las consideró «malas, con apariencia manifiesta de publicidad barata, con aseveraciones inexactas, sin expresar contraindicaciones, ni incluir buenas referencias (de estudios científicos), ni el precio». La «British Medical Association» se quejó de la publicidad y las autoridades hospitalarias la compararon a la de los detergentes. Por su parte, el mismo Comité Sainsbury concluyó que «la mayor parte de los anuncios parecen descansar sobre los trucos publicitarios empleados con generalidad (en todos los mercados)» y que «no son infrecuentes las citas de (artículos aparecidos en) oscuras revistas» (25, pág. 67).

El rechazo de los anuncios postales en los últimos años está provocando su sustitución por revistas gratuitas que, junto a la propaganda, incluyen, 
con atractiva presentación, artículos de todo tipo. En cualquier caso la bajísima calidad de la publicidad postal y su volumen incitan a preguntar por su sentido económico. Si sigue formando parte de la estrategia de ventas de las compañías, aun cuando sepan que es sistemáticamente arrojada a la basura por la mayor parte de los médicos (12), hay que concluir que se trata, antes que de un medio de diferenciación del producto e impulsión del consumo, de una barrera monopolística a la entrada de nuevos competidores en el mercado. Si en términos de eficacia publicitaria, «el envío por correo de folletos publicitarios sólo da lugar a pérdidas puras» (11, pág. 85) es que la eficacia se busca en otro ámbito: el de la reserva del mercado.

\section{e) Muestras y otros métodos de promoción de ventas dirigidos a los médicos}

Entre las piezas más gruesas de la imponente batería publicitaria farmacéutica están las muestras de medicamentos que las empresas regalan a los médicos, generalmente por vía del visitador:

«(El visitador), como otros cabilderos, no venden directamente. $\mathrm{Su}$ esperanza es congraciarse con el médico proporcionándole "información científica", aunque algo sesgada, sobre los productos de su patrón y dejándole algunas muestras para coadyuvar a que sus pacientes los usen. Antes de despedirse se ofrecerá a satisfacer graciosamente las necesidades que la familia del médico pueda tener de los productos de su empresa. Si el médico está muy ocupado - la mayor parte de los médicos lo están- y recibe un breve y simple resumen de lo que el nuevo producto es, puede, muy bien, tratar de probarlo. Para empezar tiene las muestras en sus manos... en alguna medida puede reducir con ellas los costes del paciente y... dándoselas se granjea su confianza; una receta es un subproducto natural» (4, Declaración del Dr. Small, parte 1, pág. 353).

No es extraño entonces que el volumen de muestras regaladas sea muy importante, hasta el punto de que en muchos países (por ejemplo, España) existen tarifas postales especiales para su envío. Tampoco puede sorprender que las propuestas de limitar su entrega gratuita a los casos en que el médico las solicite expresamente (25, pág. 65), hayan caído en el vacío.

También es tradicional que las compañías farmacéuticas financien congresos, reuniones, simposios, seminarios, etc. La concentración de médicos y el marchamo científico más o menos justificado convierte estas reuniones en blanco favorito de los departamentos de promoción de ventas. La financiación puede abarcar desde la cobertura de los costes estrictos hasta el abono 
de fuertes honorarios y dietas a los conferenciantes y de entradas a espectáculos musicales con derecho a consumición. La transmutación de una pretendida reunión de estudio en agradable fin de semana con todos los gastos pagados en un enclave turístico, está muy extendida en todos los países y en algunos de ellos ha exigido un control oficial cuya efectividad siempre es dudosa. Esta largueza es obvio que contribuye a ablandar la disposición de los médicos frente a las empresas subvencionantes. Además, es regla que en tales concentraciones los visitadores desarrollen una intensa actividad con el apoyo de tenderetes convenientemente coloreados e iluminados.

Otras «filantrópicas» subvenciones tienen también un valor estratégico. Si bien la porción de ingresos de las facultades americanas de medicina procedente de la Industria Farmacéutica es reducida ( 2 por 100 de sus gastos de investigación financiados por fuentes externas, en 1968), su trascendencia efectiva puede llegar a una cota muy alta: «una cátedra (financiada y por tanto bautizada) con el nombre de la empresa farmacéutica que la mantiene puede hacer que el prestigio de la institución de enseñanza superior "resbale" hacia la empresa» (16, pág. 84). La excusa científica también cubre la organización de visitas y giras para conocer, entre otros lugares de interés turístico, las excelencias de un laboratorio. Finalmente, la entrega pura y simple de regalos a los médicos también está, como todos los pacientes tienen ocasión de comprobar al visitar sus consultas, generalizadas. Y ello sin hablar de casos directamente delictivos de recentaje a comisión detectados en todos los países.

La fuerza expresiva de las cifras del cuadro 3 exime de una exposición cualitativa más detallada para la que existen testimonios y evidencias incontables. Mide la importancia de estas líneas publicitarias complementarias para 21 grandes empresas americanas, con datos comunicados por ellas mismas. Además, también figuran en su parte «A» los anuncios «pro memoria» (esto es, los enviados por correo sin texto científico) y el número de dosis contenido en las muestras regaladas por dichas 21 empresas. La enormidad de las cifras hace temblar: dos mil millones de dosis equivalen a diez dosis por americano y año. En la parte «B» se aprecia la magnanimidad con que sufragan visitas, excursiones, coloquios y conferencias, subvencionando gastos de todo tipo. Por último, el apartado «C» enumera las empresas forzadas a suministrar esta información al Senado de los Estados Unidos. 


\section{CUADRO 3}

\section{USA 1973. Actividades publicitarias de 21 empresas} farmacéuticas importantes

A) Magnitud de sus lineas publicitarias;

Linea publicitaria

Visitas y excursiones

Coloquios y conferencias $\ldots . . \ldots, \ldots .$.

$\begin{array}{lllllllllll}\text { Regalos } & \ldots & \ldots & \ldots & \ldots & \ldots & \ldots & \ldots & \ldots & \ldots & \ldots\end{array}$

Anuncios "pro memoria" ...

Muestras gratuitas
Volumen

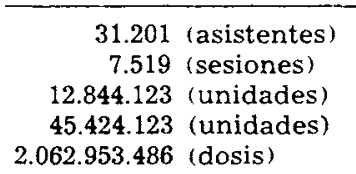

Coste en dólares

748.097

2.724 .697

5.534 .426

8.579 .974

No disponible

B) Número de compañias que declararon haber cubierto los tipos de gastos que se expresan:

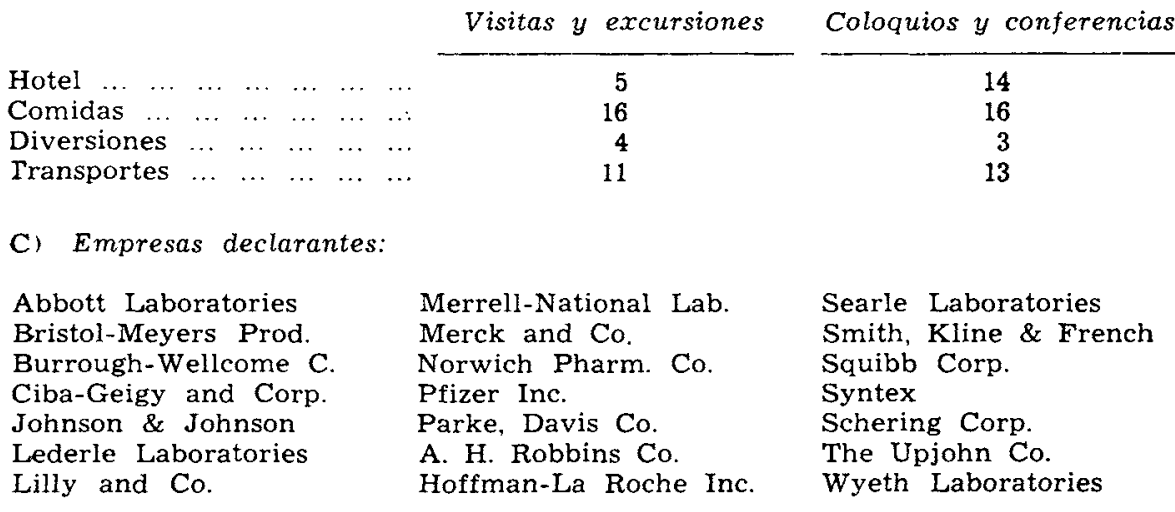

Nota: En ocasiones la cobertura de los datos no es completa ni respecto a las 21 compañías ni respecto a las actividades.

Fuente: (5, parte 4 , págs. 1418 y sigs.).

\section{f) Publicidad abierta y encubierta dirigida al público}

Existen productos farmacéuticos considerados lo suficientemente inocuos como para venderse sin receta médica. En algunos países son anunciados al público en general, muy especialmente por televisión. En los programas norteamericanos de audiencia nacional, cuyos espectadores tienen edad y renta media relativamente elevadas (telediarios), los analgésicos son objeto de publicidad obsesiva. Al Senado, que en 1971 abrió una investigación específica (42), siguió en 1972 la "Federal Trade Commission" quien inició actuaciones contra American Home Products, Bristol-Meyers y Sterling Drug, por su 
carácter desorientador y deshonesto. Levinson aludió a la lentitud con que progresaron los procedimientos y que puede hacer que la decisión, cuando se adopte, sea ya inútil (43, pág. 85 ). Otros medios, incluso los más extravagantes, son también empleados. Quien esto escribe fue invitado por una bella señorita en minifalda a saborear el nuevo gusto a naranja de unas pastillas de vitaminas a la puerta de una farmacia de un centro comercial de Los Angeles (California), en el invierno de 1975. El impacto, en términos de creación de atmósfera favorable al consumo de medicamentos, es importante. Según Levinson, "contribuye de forma decisiva al problema de la drogadicción» (43, pág. 74).

En la modelación de pautas de consumo puede muy bien ocurrir, sin embargo, que la máxima eficacia corresponda a formas de publicidad no declaradas, sino encubiertas. La crónica «científica» en la que de modo «objetivo» se da cuenta de los descubrimientos médicos es el instrumento más utilizado y conocido:

«Entre los médiços se bromea con un chiste muy divertido: que la información más reciente sobre los últimos avances de la medicina aparece en periódicos "médicos" tan "eminentes" como el Reader's Digest, el Time, y el Wall Street Journal. A veces se trata de periodismo del bueno. Pero... (la mayor parte)... ha sido colocado por los servicios de relaciones públicas de las empresas farmacéuticas» (44, Declaración de un médico, parte 18, págs. 10241 y ss.).

Una carta dirigida por una compañía de relaciones públicas a una compañía farmacéutica como cliente potencial decía:

«... Un relato de los resultados clínicos obtenidos con un nuevo fármaco... automáticamente ayuda a crear demanda por el producto. El método que tendría mejores y más directos resultados en cuanto a promoción de ventas sería un servicio informativo que proporcionase una columna con relatos médicos y de salud centrados en algún producto, para los diarios o semanarios de las ciudades pequeñas. Tanto del texto como de las ilustraciones facilitaríamos una matriz con lo que el periódico no tendría que componer ni grabar» $(45$, parte 6 , páginas 3212 y ss.).

El servicio, en el que siempre se mencionaba el nombre de un producto, se ofreció a 2.000 periódicos, muchos de los cuales lo aceptaron. El material, naturalmente, no se identifica como publicidad. Otra empresa, tras orquestar una campaña invitando a los miembros de la Asociación Americana de Escritores Científicos de Prensa a reuniones semifestivas para informarles de un nuevo producto y comunicar a la prensa sus virtudes, escribió a los médicos: 
«Querido doctor: Puede que haya leído noticias sobre un nuevo y potente ataráxico llamado $\mathrm{H}$... Es casi imposible controlar la publicidad cuando se trata de un descubrimiento científico importante. Los periodistas son inquietos y no dejan de investigar sobre $H .$. Queremos que usted sepa del producto $\mathrm{H}$... por nosotros y no por la prensa...» (12, pág. 186).

La Organización Mundial de la Salud «habiendo observado la publicación prematura en la prensa no médica, de artículos sobre medicamentos a los que con frecuencia se aplican los calificativos de "maravillosos" o "milagrosos" " ha considerado el asunto lo suficientemente grave como para encomendar al director general «que señale a la atención de los Estados Miembros la conveniencia de adoptar medidas apropiadas...» (46).

Finalmente, es preciso sacar a la luz las permanentes campañas de defensa de la imagen de la Industria como tal. Unas veces son explícitas, como la del Reader's Digest, que en los años sesenta publicó numerosos anuncios sobre las supuestas contribuciones a la ciencia de la Industria Farmacéutica americana, luego desenmascaradas (15, págs. 65 y ss.). Otras veces, muchas, son encubiertas y refinadas, como la creación, estudios y actividad editorial de la Office of Health Economics:

Pero la «Association of the British Pharmaceutical Industry financia la Office of Health Economics, que es un departamento de la Asociación. La OHE publica libros y panfletos de variada índole... algunos, aunque desde luego no todos, se refieren a los beneficios que se han alcanzado con el empleo de los productos de la Industria Farmacéutica» (25, pág. 66).

Su propio director usa una aplicación del método de previsión llamado de Delfos para diseñar una imagen futura de la Industria Farmacéutica que se ofrece al cándido lector como la más deseable, con los astutos elementos que proporcionan la mitificación del saber científico de los participantes y el carácter esotérico y supermoderno del método. El truco es que «sobre una base puramente subjetiva este último punto de vista (el de algunos participantes que predicen mayor intervención estatal) fue eliminado» (47).

La defensa es tanto más obstinada cuanto mayores o más peligrosos son los ataques. La reacción ante las investigaciones del Senado norteamericano, del Comité Sainsbury o de otros órganos gubernamentales o privados en países diversos ha cubierto todo el espectro de posibilidades que las «relaciones públicas» ofrecen. No es la menos importante la publicación de libros que en apariencia tienen un serio contenido analítico. Destaca (20) que fue escrito como respuesta a las investigaciones de la Comisión Real británica presidida por Lord Sainsbury. Muchas otras obras, seguramente la mayoría de 
las escritas sobre los problemas de la Industria Farmacéutica, no pueden ser consideradas en el fondo más que como publicidad refinada. Tres ejemplos: $(48,49$ y 50$)$.

Hay que tener en cuenta que como han argüido Reekie (51) y Scherer, «los incentivos para anunciar una gama de productos en general son más fuertes cuando el número de vendedores es pequeño que cuando es grande... Aquí es el oligopolista el que reúne lo mejor (o lo peor) de los dos mundos. Tiene rivales a quienes arrebatar ventas y participa significativamente en la expansión general de la demanda del mercado» (24, pág. 334). Por último, el círculo se cierra cuando la propia publicidad es objeto de publicidad. Dada la función vital que cumple en la estructura del mercado, es lógico que en el anuncio de las ventajas de la publicidad farmacéutica se emplee tiempo, esfuerzo y dinero (13); es, especialmente para los economistas, un ejemplo notable ${ }^{10}$.

\section{EL COSTE SOCIAL DE LA DESINFORMACION}

Las funciones económicas de la publicidad son instrumentar la diferenciación del producto y alzar una formidable barrera de entrada a la industria. Sus efectos, empero, no se limitan a la propulsión del consumo y el refuerzo de posiciones monopolísticas. En términos de costes sociales ya hemos visto la marcada ineficiencia de algunos métodos publicitarios (especialmente los visitadores) y, también, los enormes gastos implicados. Otro coste social, quizá el más importante, también ha sido mencionado. Se trata de que la publicidad distorsiona la transmisión de información farmacológica:

«El problema es saber hasta qué punto la publicidad y el marketing... contribuyen al uso inadecuado de las medicinas. Es una pregunta que no se contesta recitando todas las contribuciones importantes que la Industria ha hecho con sus investigaciones... Sólo puede ser contestada con un cuidadoso examen de su impacto sobre el proceso de adopción de decisiones por los médicos. La evidencia hasta la fecha

"Dice Teeling-Smith que "la clave de la importancia del marketing para el progreso científico reside en el hecho de que manifiestos avances no son adoptados en la práctica hasta que no son vendidos. La inmunización contra la difteria es un ejemplo clásico. Durante los años 30 alrededor de 30.000 niños fallecieron de difteria en Inglaterra porque no se empleaba la vacuna aunque ya estaba disponible; durante esa década la difteria fue virtualmente eliminada del Canadá gracias a campañas de inmunización" (pág. 42). La versión de la Encyclopaedia Britannica (William Benton Pub., Londres, 1969) es muy diferente: primero indica que en 1930-1934 se produjeron "brotes de esta clase... particularmente severos" en Inglaterra (tomo 7, pág. 471). Segundo, dice que "se ha pretendido que la erradicación de la difteria en muchas ciudades canadienses y americanas y luego en toda Gran Bretaña se debió a las campañas de inmunización profiláctica. Parcialmente esto puede resultar desorientador porque otros factores... también estuvieron presentes" (pág. 472). 
presentada indica que su influencia es sustancial, y que, además, pued muy bien no servir al interés público» (5, Declaración del senador E. Kennedy el 12 de marzo de 1974, parte 3, pág. 791).

Ya en 1902 un famoso médico inglés, el Dr. Osler, se quejaba de «la bastarda literatura que inunda nuestro correo...» y de «los hombres que comercian con la credulidad inocente del médico medio... Ni las más respetables compañías están libres de pecado» (20, pág. 212). Muchos años después los organismos más solventes y los estudios más profundos siguen denunciando la miseria de la publicidad farmacéutica. La «Task Force» americana concluye: «... En general, su valor informativo... continúa ofreciendo fuertes dudas» (17, pág. 10). Y la Organización Mundial de la Salud, tomando ejemplos de Francia, Noruega, Suecia y Holanda constata: «que ha sido y es objeto de críticas, tanto desde el punto de vista de su calidad como desde el del enorme volumen de material publicitario y muestras gratuitas enviado a los médicos (52, pág. 5). Por ello, la Resolución 41 de su 21 Asamblea (mayo $1968)$ hizo públicos unos criterios éticos y científicos aplicables a la publicidad farmacéutica.

El profesor de Farmacología Solomon Garb clasificó hace tiempo los anuncios inexactos o desorientadores en tres categorías (12, pág. 167) también señaladas por la OMS (52, pág. 5): 1) Los que contienen medias verdades. 2) Los que sólo incluyen los efectos favorables y callan los desfavorables. 3) Los que proporcionan como evidencia estudios clínicos sobre un colectivo de pacientes estadísticamente no significativo.

Analizando la primera categoría (15, pág. 58 y ss.), critica exhaustivamente la inadecuación técnica de la publicidad farmacéutica en los principales grupos de medicamentos. Fustiga la promoción de tranquilizantes orientada al «tratamiento» de los problemas ordinarios de la vida ". Las vitaminas «extra» para la población bien alimentada son inútiles y «convierten las alcantarillas americanas en las más nutritivas del mundo», ya que no son asimiladas y se excretan. Entre los antibióticos el uso del cloranfenicol, un medicamento peligroso, ha sido literalmente forzado por la publicidad.

La Investigación Kefauver proporcionó evidencia aplastante sobre la minimización de los efectos secundarios (12, pág. 171 y ss.). El «Decadron» (Dexametasona) de Merk y el «Diabinese» (Clorpropramida) de Pfizer fueron detenidamente estudiados como dos típicas modificaciones de productos ya conocidos cuya superior eficacia y ausencia de problemas secundarios se predica a los cuatro vientos, cuando en realidad son más nocivos que los ante-

$"$ Ejemplo: Sandoz y su escandalosa propaganda del Serendil: "Para la ansiedad derivada de la inadaptación; para el recién llegado que no puede hacer amigos en su nueva ciudad; para el hombre de empresa que no se ajusta a su modificado status en la compañía; para la mujer que no se entiende con su nuera; el ejecutivo que no puede aceptar el retiro. Estos comunes problemas de ajuste son en nuestra sociedad frecuentemente intolerables para una personalidad desordenada que a menudo responde con ansiedad excesiva." (15, pág. 58.) 
riores. En España investigaciones del Departamento de Farmacología de la Universidad Autónoma de Barcelona han probado, entre otras cosas, que el Vademecum Daimon no menciona las contraindicaciones en el 89 por 100 de los casos, ni efectos adversos en el 98 por 100 (53). La legislación aprobada a resultas de la Investigación Kefauver mejoró en los Estados Unidos la presentación de los efectos secundarios, pero en Inglaterra, dotada de servicios sanitarios ejemplares, el Comité Sainsbury hizo «una comparación de los anuncios aparecidos en las ediciones británica y americana de una revista médica que reveló que, refiriéndose a idénticos productos, la edición americana contenía muchá más información sobre efectos secundarios y contraindicaciones que la inglesa» (25, pág. 66). En otros países las cosas están peor. El Gráfico 1 demuestra que la publicidad financiada por empresas americanas en el Vademecum Daimon español informa mucho peor que la del PDR americano. Silverman también ha probado que las mismas empresas anuncian en Latinoamérica sin reparos productos que en USA se rodean de precauciones, e incluso cambian sustancialmente sus indicaciones terapéuticas (54).

En la actualidad se examina con detenimiento la validez científico-estadística de los estudios clínicos que evalúan sobre los pacientes la eficacia, inocuidad y seguridad de los medicamentos, y que la publicidad airea con marcada alegría. Hay muchos motivos para creer que dichos estudios en muchas ocasiones carecen de la adecuada representatividad. Los márgenes de lo que deba ser considerado como científica o estadísticamente válido no son estrechos; de ahí la dificultad de imponer normas estrictas. Ante el Senado de los Estados Unidos la empresa G.D. Searle (primer productor de la «píldora») fue acusada en 1976 de presentar ante la F.D.A. estudios con una metodología estadística inapropiada (55).

La situación ha llegado así a un extremo tal que varias facultades y escuelas de medicina - por ejemplo, las de la Universidad de California en San Francisco (56) y las citadas en (12, pág. 165)—, imparten cursos para contrarrestar los efectos nocivos de la publicidad farmacéutica y fomentar el espíritu crítico entre los estudiantes.

La conclusión es clara:

«Hay datos suficientes para afirmar que muchas de las principales compañías farmacéuticas han sido obligadas a admitir que su publicidad no era la verdad y nada más que la verdad. También está claro que... las ventas y los beneficios de casi todas las compañías principales siguen creciendo. Igualmente no hay duda de que muchos de los productos anunciados con falsedades y medias verdades, según ha demostrado la F. D. A., se han situado y continúan situándose en los primeros puestos entre los medicamentos más frecuentemente recetados por los médicos americanos» (15, págs. 66 y 67). 
PUBLICIDAD FARMACEUTICA DE EMPRESAS USA - DIFERENCIAS DE CALIDAD ENTRE EL VADEMECUM ESPAÑOL Y EL NORTEAMERICANO

ACEPTABILIDAD INDICACIONES

ESPECIFICADAS

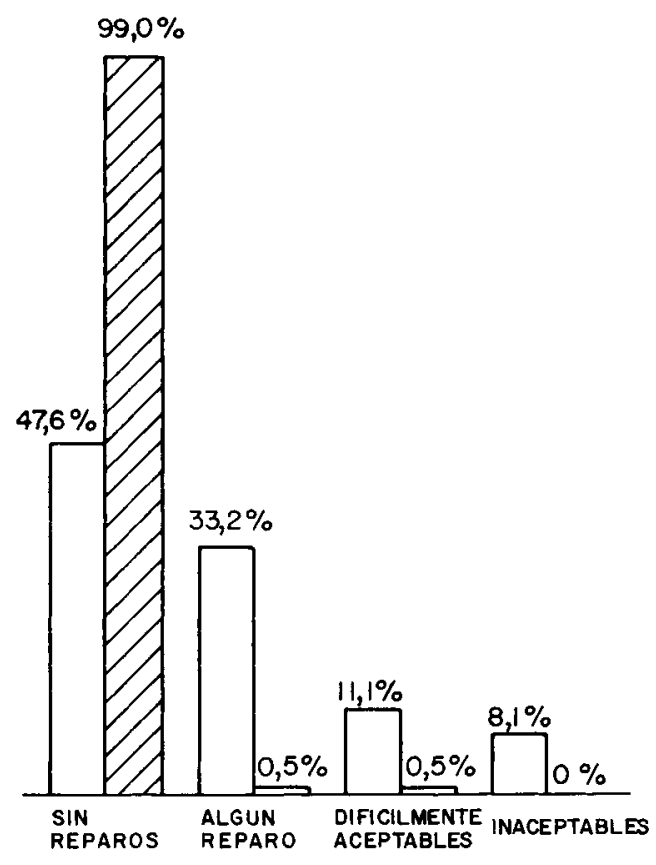

CONTRAINDICACIONES DESCRITAS ESPECIFICAMENTE (*)
EFECTOS ADVERSOS DESCRITOS ESPECIFICAMENTE (*)

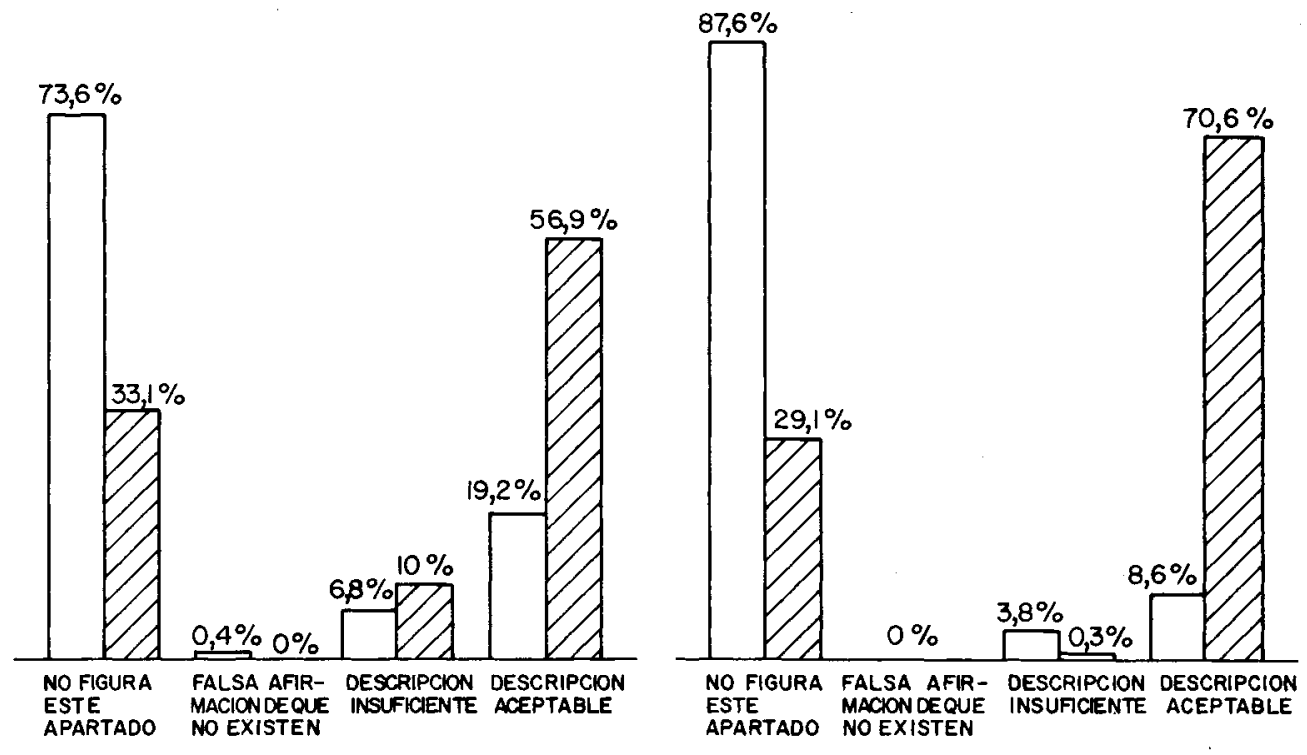

VADEMECUM DAIMON EsPañol

7 PHYSICIANS DESK REFERENCE NORTEAMERICANO * : NO ESTAN COMPUTADAS FRECUENTES REFERENCIAS DEL PDR A CONTRAINOICACIONES Y EFECTOS ADVERSOS INCLUIDAS EN OTROS APARTADOS FUENTE: DU SOUICH y otros: "La Industrio Farmacéutico Americano en Españo. Esfudio Comparativo del VD y del PDR", Anales de Medicina 1972 
«La capacidad de enjuiciamiento de los médicos está tan superada por la creciente riada de productos comercializados y la publicidad a ellos referida, que se encuentran - al igual que el público en generala merced de los poderes de persuasión de los fabricantes» (57).

El economista suma y sigue y en la cuenta de la estructura del mercado, de la que la publicidad es elemento principalísimo, debita los costes sociales de la desinformación. Nada menos que Blair, dictaminando este cargo, ha sugerido que la organización del mercado farmacéutico contiene poderosos estímulos para que se verifique una especie de «Ley de Gresham» de la publicidad (12, pág. 147).

\section{7. ¿ES POSIBLE CONTROLAR LA PUBLICIDAD?}

«Es bastante raro encontrar normas precisas o detalladas de los requisitos aplicables a la publicidad dirigida a los médicos... y cuando aparecen... usualmente contienen el principio de que dicha publicidad no está sujeta a restricción alguna» (52, pág. 10). La instrumentación de medidas de control efectivas es ciertamente muy difícil. El director del órgano inspector mejor dotado del mundo capitalista explicó bien claramente por qué: «El volumen de la propaganda es tan grande que la Food and Drug Administration sim. plemente no puede revisarla toda» (58).

Como hipotética alternativa, la Industria propicia los Códigos de Buenas Prácticas Publicitarias, acuerdos de autocontrol entre caballeros sin sanción coercitiva legal ${ }^{12}$. Muchos piensan en un nuevo camuflaje ante quienes reclaman una inspección difícilmente eficaz pero siempre incómoda para las compañías. La característica indeterminación de estos Códigos - el de la P.M.A. admite los regalos a los médicos si son de «poco» valor y el de la A.B.P.I. si son «baratos» y «relacionados» con su profesión (52, págs. 6 y 13) - y su escasa o nula ejecutividad —durante todo 1965 el Comité de Control inglés sólo se reunió dos veces y la pena máxima es la expulsión de la Asociación (25, pág. 68); sólo el 38 por 100 de los médicos sabía en 1964 del Código inglés, pero un 30 por 100 conocía prácticas publicitarias deshonestas o ilegales (28, pág. 220)_- hacen pensar que, efectivamente, sólo son pantallas de disimulo.

En los Estados Unidos, en algunos momentos, ciertas organizaciones médicas y el Gobierno Federal han intentado controlar la propaganda. American Medical Association fundó en 1914 el «Council on Pharmacy and Chemis.

12 Cabe mencionar el de la Asociación de Industrias Farmacéuticas de la EFTA, aprobado en 1963; la Proposición de Directiva del Consejo de la CEE (Journal Officiel des Communautés Européennes, núm. 248/18, de 13 de octubre de 1967), el de la "Association of the British Pharmaceutical Industry" y el de la "Pharmaceutical Manufacturers Association" de los Estados Unidos. Para un análisis más detallado, pero acrítico (52, págs. 6 y 13 ). 
try», llamado luego «Council on Drugs». En 1929 creó el «Seal of Acceptance», de calidad técnica para los medicamentos, sin el cual no podían ser anunciados en sus revistas. En 1955 abolió uno y otro ante el estancamiento de sus ingresos por publicidad, y desde entonces acepta indiscriminadamente casi cualquier anuncio (15, págs. 63 y ss.). En 1914 los medicamentos fueron exceptuados del control de la Federal Trade Commission, «seguramente porque se pensó que los médicos son demasiado astutos como para ser desorientados por la publicidad» (15, págs. 63 y ss.). En 1938, una confusa regulación atribuyó la vigilancia de la publicidad a la F.T.C. y del etiquetado a la F.D.A. Desde 1948 se interpreta que la «etiqueta» abarca toda propaganda escrita, lo que mejoró los controles oficiales de calidad pero no los de publicidad. Desde 1966 se fuerza a las compañías con publicidad juzgada inaceptable a enviar "contrapublicidad» en forma de cartas de rectificación a los médicos.

«Decir que nuestros servicios han tenido dificultades con las afirmaciones hechas por muchas companías farmacéuticas en su publicidad es subestimar la experiencia del año pasado. Básicamente, el problema radica en la inclinación de ciertas empresas a desbordar los textos aprobados y evadir las normas que exigen una declaración breve y honesta de todo lo bueno y lo malo que se puede esperar de un fármaco. Es una situación extraña, ya que a veces la F.D.A. no ha sido tan estricta como hubiera podido. Pero incluso cuando gozan de una cierta laxitud algunas compañías ansían más» (4, Declaración del Dr. James L. Goddard, «Commissioner» de la F.D.A., parte 2, pág. 808).

\section{ALTERNATIVAS A LA DESINFORMACION PUBLICITARIA Y ALTERNATIVAS AL MERCADO}

Aunque por el papel central de la publicidad en la estructura monopolística del mercado la industria con todas sus fuerzas lo niega ${ }^{13}$, es bastante obvio que «la publicidad no es la única forma de proporcionar información... Hay expertos... que pueden juzgar y valorar los fármacos y reducirlos... a un grupo de dimensiones razonables y dar toda la información que el médico puede asimilar y usar. ¡Qué duda cabe!» (4, Declaración del Dr. Cherkasky, parte 2, pág. 682).

La OMS ha descrito así la alternativa en su tenor general:

1.3 Por ejemplo, por boca de la OCDE: “... En ciertas economías planificadas... ha habido que recurrir a los visitadores médicos. Nadie ha podido demostrar la existencia de un método más eficaz que la práctica comercial normal de promoción de ventas para conseguir que las nuevas medicinas sean rápidamente adoptadas..." (11, pág. 86). 
«...El aumento constante del número de medicamentos nuevos, de actividad y toxicidad cada vez mayores, impone a los médicos... la obligación inexcusable de mantenerse al corriente de los adelantos de la farmacoterapia.»

«Algunos países organizan servicios de información farmacológica para: $\left.1 .^{\circ}\right)$ perfeccionar sus conocimientos asistiendo a cursos ordinarios en instituciones académicas, a conferencias especiales de profesores universitarios, a reuniones, debates y prácticas en hospitales. $2 .^{\circ}$ ) recibir información completa sobre medicamentos nuevos (incluidos el precio y la opinión que merecen a especialistas no oficiales), por medio de circulares y boletines difundidos por las autoridades sanitarias nacionales; y $\left.3 .^{\circ}\right)$ recibir los resúmenes críticos publicados sobre medicamentos nuevos o en uso por asociaciones de médicos y otros organismos autónomos, en revistas de medicina, anuarios y grabaciones magnetofónicas» (13, pág. 12).

La iniciativa más simple —propugnada en Inglaterra y USA por el Comité Sainsbury, la Task Force y la FDA - consistiría en que un organismo público de carácter técnico e independiente «publicara y distribuyera regularmente entre los médicos... una lista que contuviera todos los detalles relevantes acerca de las especialidades farmacéuticas» (25, pág. 3), «que incluya información sobre extremos tales como formas y dosis disponibles, efectos clínicos, indicaciones y contraindicaciones, métodos de administración y datos sobre precios de cada producto, y que sea completa y manejable» (17, página 24). En ninguno de los dos países ha sido puesta en práctica. La oposición de la «American Pharmaceutical Manufacturers Association» a que las especialidades fueran descritas por sus nombres genéricos y enumeradas en índices cruzados, en los que constasen fabricantes y nombres comerciales demuestra que, a costa de una mejor información de los médicos, no quiso hacer más transparente y competitivo el mercado, sino proseguir con la diferenciación del producto (Véase 4, Declaración del Dr. James L. Goddard, "Commissioner» de la FDA, el 9 de noviembre de 1967, parte 4, págs. 1219 y ss.).

En los Estados Unidos AMA ha mantenido algunas publicaciones críticas, pero finalmente han sido vencidas por la oposición de la Industria ${ }^{14}$. En dicho país sólo sobrevive, a pesar de que hay que pagar por recibirla, alguna publicación independiente como Medical Letter, que "proporciona una crítica valiente y objetiva de medicamentos nuevos y antiguos» (16, pág. 6). En Inglaterra destaca el Prescriber's Journal del Ministerio de Sanidad, pero

${ }_{14}$ Dejó de publicar el Epitome of the Unites States Pharmacopeia and National Formulary a principios de los años 50; en 1957 interrumpió la edición de New and Non Official Remedies, y en el mismo 1974 nació y, por presiones de la "Pharmaceuticals Manufacturers Association," murió, AMA Drug Evaluations (16, págs. 22 y ss.). 
ésta y otros revistas ${ }^{15}$ no impiden que «la situación sea bastante típica... la mayor parte de los médicos aprenden lo que saben sobre el uso y el abuso de los medicamentos modernos gracias a quienes los fabrican» (18, págs. 70 y 71).

En este último país el Comité Sainsbury también propuso un «documento de control» que, elaborado por un organismo público, sirviera como patrón de contraste para la publicidad escrita, fuera enviado a los médicos antes de iniciarse la campaña publicitaria y «los visitadores siempre lo exhibirían» (25, pág. 3). A pesar de su moderación, esta reforma tampoco ha sido llevada a la práctica.

Estas frustraciones americanas e inglesas demuestran que la sencillez técnica de la alternativa al sistema publicitario de desinformación se estrella contra el muro de la estructura monopolística y que la calidad de la información farmacéutica es una cuestión inseparable del resto de los factores que definen el mercado y sólo puede ser abordada eficazmente en el seno de una acción de conjunto.

«Si se proporcionara información adecuada y objetiva los gastos de publicidad seguramente no bajarían en absoluto, e incluso podrían subir, al tratar cada empresa de contrarrestar los esfuerzos publicitarios de las otras y, además, los nuevos datos independientes... a no ser que se adoptaran otras medidas...» (4, Declaración de H. Steele el 19 de enero de 1968, parte 5, pág. 1919).

\section{A N E X O}

\section{1) El caso del Cloranfenicol-Cloromicetin de Parke Davis}

Hacia 1950, se comprobó que el cloranfenicol, antibiótico indicado para la fiebre tifoidea, tiene peligrosos efectos secundarios en caso de uso indiscriminado, especialmente una enfermedad fatal y de difícil diagnóstico (anemia aplástica). El Council on Pharmacy and Chemistry de la AMA así lo advertía en la edición 1951 de New and Nonofficial Remedies. También lo hacía el editorial del Journal of the American Medical Association, de 28 de junio de 1952. En junio de 1952 la «Food and Drug Administration» interrumpió su certificación ${ }^{16}$; poco después, el National Research Council (NRC)

1. Sobre el Prescriber's Journal (que no compara los méritos relativos de los medicamentos); la Prop List (referente a medicinas sin receta que también se publicó con ayuda oficial hasta que "según algunos cínicos" las presiones de la industria la eliminaron), el Drug and Therapeutics Bulletin de la Consumer's Association, el Lancet y el British Medical Journal, véase (18).

16 La FDA contrasta la calidad de todos los lotes de antibióticos producidos en Estados Unidos. Sin su certificación su venta es ilegal. 
recomendó que el producto sólo siguiera en el mercado si se advertía el riesgo de discrasia sanguínea y que no debía ser usado indiscriminadamente, para afecciones menores o en períodos largos sin control de los componentes sanguíneos. La FDA puso en vigor estas recomendaciones. La reacción «com. pensadora» del departamento de ventas del fabricante, Parke Davis, fue inmediata. En las instrucciones a sus vendedores, reveladas por el Comité Kefauver, hizo aseveraciones falsas:

«Cloromicetín (nombre de marca del Cloranfenicol) ha sido aprobado sin restricciones por la FDA y el NRC en cuanto al número y la amplitud de las enfermedades (para cuyo tratamiento puede ser administrado)» (Subrayado en el original) (12, pág. 194).

También hizo afirmaciones desorientadoras:

"Cloromicetín ha superado tres investigaciones intensivas: la original de Parke Davis; la de los funcionarios de la FDA y después la de un comité especial formado por autoridades en los campos de la hematología y la quimioterapia nombrados por el NRC» (12, página 194).

«Las recientes decisiones... indudablemente constituyen el más alto cumplido nunca hecho al equipo médico de nuestra empresa» (12, página 195).

Igualmente proporcionó a los visitadores instrucciones para silenciar el problema:

«El detalle especial PP10 (es decir, el conjunto de argumentos y material gráfico destinado a aliviar las aprensiones del médico frente al Cloranfenicol) no debe ser presentado a no ser que el médico plantee por sí mismo el tema, o usted (el visitador) esté seguro de que ha dejado de recetar la medicina» (12, pág. 196).

Y trató de minimizar las advertencias dictadas por la FDA, de inserción obligatoria en los anuncios, describiéndolas únicamente como

«Una juiciosa precaución contra su indiscriminado uso (del Cloranfenicol) que en nuestra opinión sería apropiada para cualquier agente quimioterapéutico potente» (12, pág. 196).

También es interesante resaltar que las normas de la FDA fueron seguidas al pie de la letra en los anuncios en revistas médicas; "dulcificadas» en la publicidad enviada por correo y simplemente tergiversadas y falseadas en el caso de los visitadores. Todo ello porque «las instrucciones (a los visita- 
dores) sólo llegan a ser conocidas por tres de las partes implicadas: las compañías que las idean, los visitadores que las memorizan y transmiten y los doctores que en último término las reciben» (12, pág. 198).

\section{2) El caso del «Mellaril» de Sandoz}

Instrucciones de Sandoz a sus visitadores en 1959 para la promoción en los Estados Unidos del tranquilizante Mellaril:

"Deben seguir promocionando Mellaril hasta que convenzan al médico de que debe usarlo. Esta es su único misión... Es imperativo que consigan que Mellaril termine por estar almacenado en todos los hospitales posibles. Este es el primer gran obstáculo a superar. El programa publicitario por correo del Mellaril es el más grande en la historia de Sandoz. Hasta primero de noviembre 1.300 .000 envíos postales llegarán a los médicos. Debido al período de vacaciones los envíos de julio y agosto serán menores que los de septiembre, octubre y noviembre, altamente concentrados. Los tests demuestran que lo que un comprador retiene más tiempo es lo que primero oye. Si los beneficios se enumeran antes que las contraindicaciones se crea una disposición mental de que «eso es para mì. Si los inconvenientes se mencionan antes, se crea una actitud de «no, gracias». (El subrayado es mío.)

Y en 1961 prepara a sus visitadores para una reunión de organización de ventas del Mellaril, diciéndoles que:

«Cada visitador ha de estudiar e interpretar los detalles previamente planificados hasta que los domine con perfecta soltura (y tenga) las inflexiones de voz apropiadas y los necesarios movimientos» (5, parte 1, pág. 141).

\section{El caso del anticonceptivo «Enovid» de G.D. Searle}

En el período de lanzamiento por Searle de un nuevo tamaño de Enovid, llamado Enovid-E 21, sus instrucciones a los visitadores decían:

«La tentación más cómoda sería vender Enovid-E 21. Debemos resistirla. El objetivo primario es vender toda una familia de productos Searle... Ahora, hablen con esa enfermera tan simpática, díganle al doctor que está muy bien informada. Que atenderá muy bien a sus pacientes... Planifiquen sus llamadas a la enfermera como si se tratase 
de llamadas al médico. Lo harán muy bien si le telefonean con anticipación y le dicen cuándo irán a verla y conciertan una cita. ¿Conocen su nombre? ¿Sabe ella el suyo?... Las muestras son preciosas. Insistan en preguntar a todos los médicos por sus necesidades y hagan todo lo posible por satisfacerlas. Cada vez que apartan a un doctor de su absorbente trabajo él está mereciendo la mejor presentación; no una hecha a medias, o sin planear. Quiere comprar. Está esperando que se le hable del negocio. Se lo dará al mejor vendedor. Será favorable o desfavorable según el entusiasmo, apariencia y maneras que ustedes muestren. Véndanle a la enfermera. Para promocionar su producto ella es tan importante como la gasolina para mover un coche. No pueden ir lejos si falla alguno de los dos» (5, parte 3, pág. 1245).

Todo ello le hace concluir al senador Kennedy:

«Hemos revisado estos archivos que cubren un período de un año... Indican que el énfasis está en las técnicas de ventas, concentrándose especialmente en la aproximación a las enfermeras y en dejarles algún regalito...» (5, Declaración del 13 de marzo de 1974, parte 3, página 1245). 


\section{BIBLIOGRAFIA}

(1) LoBo, Félix: "La industria farmacéutica. Materiales para el estudio del crecimiento del capitalismo español en los años 60 . Análisis económico de un sector industrial modelo", tesis doctoral dirigida por el profesor doctor Juan Velarde Fuertes, Facultad de Ciencias Económicas y Empresariales, Universidad Complutense, Madrid, 1977.

(2) Chamberlin, E. T.: Teoría de la competencia monopólica, 2. ${ }^{a}$ ed. en español, Fondo de Cultura Económica, México, 1956; Robinson, Joan: The Economics of. Imperfect Competition, Londres, 1945.

(3) Barn, Joe S.: Barriers to New Competition, Harvard University Press, Cambridge, Mass, 1956.

(4) U. S. Congress, Senate, Select Commitee on Small Business, Subcommitee on Monopoly: Hearings, Competitive Problems in the Drug Industry, USGPO, Washington, 1967 et seq., investigación dirigida por el senador Gaylord NELSON.

(5) U. S. Congress, Senate, Committee on Labor and Public Welfare, Subcommittee ON HEALTH: Hearings, Examination of the Pharmaceutical Industry 1973-1974, USGPO, Washington, 1973 et seq., investigación dirigida por el senador Edward KENNEDY.

(6) Comanor, William S.: "Research and Competitive Product Differentiation in the Pharmaceutical Industry, in the United States", Económica, vol. 31, número 124, noviembre de 1964, pág. 380 .

(7) Standard and Poor's: Industry Surveys. Health Care, Drugs and Cosmetics, Basic Analysis, Nueva York, 10 de julio de 1975, pág. 15.

(8) Comanor, William S., y Wilson, Thomas A: "Advertising, Market Structure and Performance", The Review of Economics and Statistics, vol. 49, núm. 4, noviembre 1967.

(9) Lово, Félix: "Estructuras monopolísticas y análisis industrial en España. El caso de la industria farmacéutica", Boletín de Estudios Económicos de Deusto, vol. 32, núm. 102, diciembre 1977 .

(10) Steele, Henry: "Monopoly and Competition in the Ethical Drug Market", The Journal of Law and Economics, vol. 5, octubre de 1962.

(11) Organización de CoOperación y Desarrollo Económico (OCDE): Ecarts Technologiques. Produits Pharmaceutiques, Paris, 1969.

(12) U. S. Congress, Senate, Commitee on the Judiciary, Subcommitee on Antitrust And Monopoly: Administered Prices: Drugs (The Kefauver Report), USGPO, Washington, 1961.

(13) Tezling-Smith, George: "The Role of Marketing in Scientific Progress", en el volumen recopilado por él mismo, Science, Industry and the State, Office of Health Economics, Pergamon Press, Londres, 1965.

(14) Walker, Hugh D.: Market Power and Price Levels in the Ethical Drug Industry, University of Indiana Press, Bloomington (Ind.), 1971.

(15) Sulverman, Milton, y LeE, Philip R.: Pills, Profits and Politics, University of California Press, Berkeley, 1976.

(16) Burack, Richard: New Handbook of Prescription Drugs, Ballantine, Nueva York, 1975.

(17) Task Force on Prescription Drugs: Final Report, U.S. Department of Health, Education and Welfare, USGPO, Washington, 1969.

(18) Doctor Gould, Donald: "Can We Handle Modern Drugs?", The New Scientist, 23 de mayo de 1974, pág. 462.

(19) ORganización Mundial dE LA SAlud: Calidad, inocuidad y eficacia de los medicamentos, informe del director general a la XXV Asamblea de la Salud, Ginebra, 16 de marzo de 1972, apéndice 1, pág. 11.

(20) Cooper, Michael H.: Prices and Profits in the Pharmaceutical Industry, Pergamon Press, Oxford, 1966.

(21) Simmons, Henry E.: "Solutions to the Communications Gap with the Practicing Physician", Conferencia ante la American Association for the Advan- 
cement of Science, Chicago (Ill.), el 20 de diciembre de 1970. Reproducida en (4, parte 21 , págs. 8438 y ss.).

(22) KrPLING, Stewart W. (Managing Director, Nicholas Laboratories), y Jones, Robert H.: "Marketing Strategies", en TeEling-Smith, George (recop.): Economics and Innovation in the Pharmaceutical Industry, Office of Health Economics, Londres, 1969, pág. 69.

(23) Declaraciones de un directivo de la compañía A. H. Robbins, citadas por KATz, Bárbara V.: "The IUD'S Unnatural Birth", National Observer del 8 de septiembre, y reproducidas en el testimonio del senador Gaylord Nelson en (5, parte 1 , pág. 145 )

(24) Scherer, F. M.: Industrial Market Structure and Economic Performance, Rand Mc Nally, Chicago, 1973, pág. 329.

(25) Commitee of Enquiry Into the Relationship of the Pharmaceutical Industry With the National Health Service 1965-1967: Report (Sainsbury Report), HMSO, Londres, 1967 (cmnd 3410).

(26) WILDER, Ronald P.: "Advertising and Interindustry Competition: Testing a Galbraithian Hypothesis", The Journal of Industrial Economics, vol. 22, número 3, marzo 1974, pág. 218.

(27) Naciones Unidas. Conferencia para el Comercio y el Desarrollo (UNCTAD), Secretaría: Major Issues on Transfer of Technology to Developing Countries. A Case Study of the Pharmaceutical Industry, Ginebra, 1975.

(28) The Monopolies Commission: Chlordiazepoxide and Diazepan, HMSO, Londres, 1973.

(29) Steele, Henry: "Patent Restrictions and Price Compettion in the Ethical Drug Industry", Journal of Industrial Economics, vol. 12, núm. 3, junio 1964.

(30) Eurofinance: The West European Pharmaceutical Industry, 1960-1980, Ginebra, 1971.

(31) KLAPPER, Joseph T.: Efectos de las comunicaciones de masas (1961), versión española de Editorial Aguilar, Madrid, 1974.

(32) Applied Management Sciences: Survey of Drug Information Needs and Problems Associated With Communications Directed to Practising Physicians, Part I, Physician Information Survey; Part II, Drug Bulletin Survey, y Part III, Remedial Advertisement-Program, reproducido en (5, parte 5, páginas 1548 y ss., 1861 y ss., y 1998 y ss., respectivamente).

(33) Dictionnaire Vidal, O.V.P., París.

(34) Rote Liste, Editio Cantor, Aulendorf, Württ.

(35) L'Informatore Farmaceutico. Annuario Italiano dei Medicamenti e dei Laboratori, Organizzazione Editoriale Medico-Farmaceutica, Milán.

(36) Monthly Index of Medical Specialities (MIMS), Haymarket Pub. Ltd.; Londres.

(37) Vademecum Internacional de Especialidades Farmacéuticas y Biológicas Daimon, Ediciones Daimon, Manuel Tamayo, Barcelona.

(38) Indice Mensual de Especialidades Terapéuticas Intercon, Ediciones J. G. Peri, Madrid.

(39) Dedef, Ediciones Dedef, San Sebastián.

(40) Chemical Economic Development Committee, Pharmaceuticals Working Party: Focus on Pharmaceuticals, NEDO, HMSO, Londres, 1972, pág. 83.

(41) Coleman, V.: The Medicines Man, Temple Smith, Londres, 1974, pág. 96. Citado en (27 pág. 43 ).

(42) U. S. Congress, Senate, Select Committee on Small Business, Subcommittee oN MoNopoly: Effect of Promotion and Advertising of Over-the-Counter Drugs on Competition, Small Business, and the Health and Welfare of the Public, USGPO, Washington, 1971 et sequ.

(43) Levinson, Charles: The Multinational Pharmaceutical Industry I.C.P., Suiza, 1972.

(44) U. S. Congress, Senate, Commitee on the Judiciary, Subcommitee on AntiTRUST AND Monopoly: Hearings. Administered Prices in the Drug Industry, USGPO, Washington, 1960, Investigación dirigida por el Senador Kefauver. 
(45) U. S. Congress, Senate, Commitee on the Judiciary, Subcommitee on AntiTRUST AND MONOPOLY: Drug Industry Antitrust Act (S. 1552), Hearings, USGPO, Washington, 1962 , parte 6 , págs. 3212 y ss.

(46) Organización Mundial de la Salud: 76 Resolución de la 5. Asamblea Mundial de la Salud. En el mismo sentido las resoluciones 35 de la 20.* Asamblea, de mayo de 1967, y la $24 .^{a}$ de la 41 Reunión del Comité Ejecutivo de la OMS, de enero de 1968.

(47) Teeling-Smith, George: "Medicines in the 1990'S: Experience with a Delphi Forecast", Long Range Planning, vol. 3, núm. 4, de junio de 1971.

(48) Happold, F. H.: Medicine at Risk, Queen Anne Press, Londres, 1967.

(49) Davies, Wyndham: The Pharmaceutical Industry. A Personal Study, Pergamon Press, Oxford, 1967.

(50) Breckon, Williams: The Drug Makers, Eyre Methuen, Londres, 1972.

(51) REEKIE, W. Duncan: "Some Problems Associated with the Marketing of Ethical Pharmaceutical Drugs", The Journal of Industrial Economics, noviembre de 1970 , págs. 35 y 36.

(52) Organización Mundial de la Salud: Pharmaceutical Advertising: A Survey of Existing Legislation, 1968, Revisión, Ginebra, 1968.

(53) Erill, García Sevilla y Laporte: "Las especialidades farmacéuticas en España. Un análisis del Vademecum Daimon 1971", Anales de Medicina, 59, 302-315, 1973.

(54) Silverman, Milton: The Drugging of the Americas, University of California Press, Berkeley y Londres, 1976.

(55) Información directamente recogida por el autor de un noticiario de televisión.

(56) Información recogida directamente por el autor.

(57) International Social Security Association: Volume and Cost of the Supply of Medicaments, 13 Informe adoptado por la 18." Asamblea General (Abidjan, 1973), Ginebra, 1974, pág. 32.

(58) DR. Godpard (Commissioner de la F.A.D.): Conferencia en la Harvard Medical School el 22 de marzo de 1967, citado por el Dr. Burack en su testimonio en (4, parte 1, pág. 314). 